\title{
Using section 27 to open up the accessibility of smoking cessation health services in South Africa
}

\author{
S Nyatsanza, LLB (Hons), LLM, PhD \\ Mandela Institute, Johannesburg, South Africa \\ Corresponding author: S Nyatsanza (nyatsanza.sharon@gmail.com)
}

Owing to the addictive nature of tobacco products, an effective smoking cessation strategy is key in curbing the tobacco epidemic and promoting health rights. Unaided attempts to cease tobacco consumption are mostly unsuccessful, giving smoking cessation a central role in the fight against the tobacco epidemic. After examining South Africa (SA)'s tobacco control policy, this article argues that to a large extent, the accessibility of both non-pharmacological and pharmacological interventions to treat tobacco dependence is still limited. The central argument made is that the right to access healthcare services under section 27 of the Constitution can be used to unlock access to smoking cessation services. Smoking cessation services should be prioritised as an important subset of the right to access healthcare services in SA.

S Afr J Bioethics Law 2019;12(2):57-60. https://doi.org/10.7196/SAJBL.2019.v12i2.668

Globally, there is considerable evidence that implicates tobacco as a major human health hazard, killing an estimate of 6 million people annually, and it is expected to be the leading preventable cause of death by $2020 .{ }^{[1]}$ The tobacco epidemic remains a major concern in South Africa (SA), with one-third of all deaths in males aged $>35$ years ascribed to tobacco use, ${ }^{[2]}$ and smoking-related diseases costing an estimated ZAR59.12 billion to the economy. ${ }^{[3]}$ This encompasses the 'direct costs related to healthcare expenditures and indirect costs related to lost productivity due to early mortality and morbidity. ${ }^{\text {[3] }}$ The public health concerns around smoking are also best viewed in the context of the HIV/AIDS and tuberculosis (TB) epidemics that face $\mathrm{SA}_{1}{ }^{[4]}$ as evidence shows that smoking is an important factor for TB infection and mortality. ${ }^{[4]}$

Tobacco contains nicotine, a highly addictive drug, and the World Health Organization (WHO) has recognised tobacco dependence as a chronic disease. ${ }^{[4]}$ Unaided attempts to cease tobacco consumption are mostly unsuccessful: more than $70 \%$ smokers want to quit, but $<50 \%$ of smokers succeed in stopping permanently before the age of $60 .{ }^{[5]}$ This shows the importance of aiding smokers in quitting tobacco consumption. Yet in SA, access to smoking cessation services is limited. ${ }^{[6]}$

\section{The disease of tobacco addiction}

Promoting smoking cessation is a major determinant in the reduction of tobacco-related deaths. ${ }^{[4]}$ The benefits of smoking cessation are immediate: within 20 minutes, the heart rate and blood pressure drop, and within 10 years, the risk of lung cancer falls to about half that of a smoker. ${ }^{[7]}$

A cessation programme should include both non-pharmacological and pharmacological interventions. Non-pharmacological or behavioural interventions include counselling and motivational interviews, and cognitive behavioural therapy, ${ }_{1}^{[4]}$ whereas pharmacological interventions include nicotine replacement therapies, antidepressants and nicotine vaccines. ${ }^{[2]}$ These intervention methods work best when they are used together, ${ }^{[4]}$ evidence shows that the interventions are most effective and cost-effective when used in combination, as there is a significant increase in successful quit attempts. ${ }^{[8,9]}$ Nevertheless, there is a paucity of cessation programmes in many states, SA included. ${ }^{[9,10]}$

\section{Smoking cessation in South Africa and beyond}

The existence of a smoking cessation programme is only the starting point. Such a programme must be accessible and available. It must be guaranteed for the wider community equitably, meaning that any smoking cessation services must be affordable and physically accessible where and when needed. ${ }^{[1]]}$ The availability of adequate and appropriate medication and services to support the smoking cessation programme would be ideal. ${ }^{[9]}$ Nonetheless, the ideal full realisation of socioeconomic rights such as the right to healthcare is not always attained. The same is true for smoking cessation services. This section gives a brief overview of the English smoking cessation programme, and compares it with the one in SA. The objective is to show that the existing smoking cessation programme in $\mathrm{SA}$ is far from comprehensive.

England has one of the most comprehensive smoking cessation programmes in the world in place, with significant steps having been taken to ensure that smokers receive the institutional support required. ${ }^{[12]}$ This programme was developed progressively. At the beginning, pilot areas were chosen for their levels of social and economic deprivation. ${ }^{[12]}$ Resources were provided to train cessation counsellors at primary care level, and to build up the required human resources. This was supported by the idea that primary care is the point of contact, and counselling is necessary to sustain quit attempts. ${ }^{[12]}$ Although most primary care nurses have been trained in cessation counselling, a co-ordinator and smoking cessation 
counsellors are also stationed at each local service. Services staffed by trained 'stop-smoking advisors' are available all over the country, and citizens have the choice of joining local groups that meet weekly or having one-to-one support. ${ }^{[12]}$

Pharmacological intervention is also accessible and available in England. The first-line treatments nicotine replacement therapy (NRT), bupropion and varenicline, are highly accessible. ${ }^{[12]}$ The pharmacotherapies are available on the National Health Service (NHS). NRT is obtainable by prescription, over the counter and in local supermarkets, while bupropion and varenicline are available only on prescription. ${ }^{[12]}$ The state has subsidised the cost of first-line therapies, making them more affordable for all citizens. Furthermore, economically disadvantaged smokers receive the pharmacotherapies for free. ${ }^{[12]}$

The UK government was motivated by three facts: that smoking addiction is a disease; that treatment of tobacco dependence is effective; and that helping smokers to quit is one of the most economical interventions that a health service can provide. ${ }^{[12]}$

Conversely, although SA has made progress in putting in place a smoking cessation programme, its accessibility remains questionable. Smoking cessation counselling is available through various quitline services provided by private organisations. The National Council Against Smoking (NCAS), the Cancer Association of SA (CANSA) and Smokenders all provide behavioural support to smokers. ${ }^{[1,15]}$ The NCAS provides quitline services and material in brochure form to help smokers quit, CANSA has an online smoking cessation programme and Smokenders Free for Life have a paid 6-week programme where face-to-face and group support is provided. However, behavioural intervention remains an underexploited segment of tobacco control in SA. ${ }^{[15,16]}$ Evidence shows scant and inconsistent availability of smoking cessation behavioural support in primary care facilities ${ }^{[6,10]}$ According to the WHO, behavioural intervention was not consistently offered in public hospitals or health clinics in SA as of December 2016, and the government does not cover the cost of such support. ${ }^{[6]}$ The state must provide resources for the adequate training of the healthcare providers needed to implement comprehensive counselling at primary healthcare facilities.

A behavioural support programme should identify smokers, alert them about the harms of tobacco consumption and assess their readiness to quit and their dependence on nicotine..$^{[2]}$ It must then determine the best combination of counselling and pharmacotherapy for the individual, follow up, monitor side-effects and provide support for relapses. ${ }^{[2]} \mathrm{A}$ once-off counselling session is only a starting point: to sustain the quit attempt and increase the chances of success, behavioural interventions are a requisite throughout the process. ${ }^{[2,8]}$

Similarly to the case in England, first-line pharmacotherapies are available in SA: NRT is available over the counter, while bupropion and varenicline are only available on prescription. ${ }^{[6]}$ Contrary to the English scheme, the SA state does not subsidise or cover the cost of pharmacotherapies. ${ }^{[6]}$ Smokers have to bear the cost of treatment; the risk is that those who cannot afford it will not be able to access pharmacotherapy. If it is to benefit the economically disadvantaged, the state must subsidise and/or fully cover the cost. Furthermore, free access to pharmacotherapy has been shown to be more effective than self-funding in smoking cessation. ${ }^{[9]}$
Evidence shows that combining expert behavioural support with pharmacotherapy is the most effective cessation strategy. ${ }^{[9,16]}$ Compared with unaided smoking cessation attempts, NRT makes it one-and-a-half times more likely for a person to succeed, while varenicline and bupropion double the chance of success in quitting attempts. ${ }^{[16]}$ On the other hand, combining pharmacotherapy with expert support makes someone up to four times as likely to stop smoking successfully. ${ }^{[16]} \mathrm{A}$ tailored approach, including accessible and appropriate intensive behavioural intervention and pharmacotherapy, is desirable to provide the best chances of tobacco cessation success, and this is still lacking in SA. Regrettably, access to treatment for tobacco dependence is still at infancy levels in SA; to a large extent, it is not accessible and available for the wider population. The WHO director for tobacco control has expressed lament over the failure of public health sectors globally to invest in smoking cessation services. ${ }^{[9]}$ Such neglect violates the human right to accessible healthcare, and section 27 is a potential tool that should be used to drive and to improve access to smoking cessation.

\section{Section 27 of the Constitution and what it can do}

Section 27 of the SA Constitution provides that:

'(1) Everyone has the right to have access to (a) healthcare services, including reproductive healthcare; (b) sufficient food and water; and (c) social security, including, if they are unable to support themselves and their dependents, appropriate social assistance.

(2) The state must take reasonable legislative and other means within its available resources to achieve the progressive realisation of each of these rights. (3) No-one may be refused emergency treatment. ${ }^{\prime[17]}$

Section 27(1)(a) imposes positive obligations on the state to progressively realise and secure access to healthcare services, within its available resources, through the implementation of reasonable legislative measures and programmes. If the state fails to fulfil these obligations, it is essentially in violation of people's socioeconomic rights. ${ }^{[18]}$ The positive obligations imposed by the right to healthcare can be employed to drive the provision of accessible healthcare services.

In accordance with section 39(b) of the Constitution, the right to access healthcare services must be interpreted in consideration of international law. Additionally, section 233 states that courts 'must prefer any reasonable interpretation of the legislation that is consistent with international law over any alternative interpretation that is inconsistent with international law.' As such, in determining both the context of 'healthcare services' and the obligations imposed on the state by section 27 , international law must be considered. ${ }^{[19]}$ For the purposes of this article, the right to healthcare services will be interpreted in light of the International Covenant on Economic and Social and Cultural Rights (ICESCR) ${ }^{[20]}$ and the WHO's Framework Convention on Tobacco Control (FCTC). ${ }^{[21]}$ The ICESCR, though not ratified in $\mathrm{SA}$, has had a remarkable impact on the development of $\mathrm{SA}$ socioeconomic rights jurisprudence. ${ }^{[18]} \mathrm{SA}$ has ratified and is bound by the FCTC, a modern-day global public health treaty providing a global co-ordinated strategy, and steps for states to take to combat the tobacco epidemic. ${ }^{[21]}$ 
With regard to healthcare services, the United Nations (UN) Committee on Economic and Social and Cultural Rights (CESCR) states that the meaning of the term 'healthcare services' will vary depending on a country's level of development. ${ }^{[2]}$ Section $27(1)(a)$ is broad enough to include all 'claims to all services, goods and facilities aimed at securing the greatest attainable standard of physical and mental wellbeing! ${ }^{\prime 23]}$ Healthcare services are not limited to hospitals and/ or essential medicines. ${ }^{[23]}$ They extend to preventive, curative and rehabilitative services. ${ }^{[22]}$ It is also important to emphasise that health determinants evolve: tobacco control is now well recognised as an underlying determinant of health. UN member states have recognised that 'substantially reducing tobacco consumption is an important contribution to reducing non-communicable diseases.'24] The CESCR indicates that states would be in violation of the obligation to protect if they omit or fail to regulate or discourage production, marketing and consumption of tobacco. ${ }^{[22]}$ Smoking cessation services form part of the obligation to discourage and regulate the consumption of tobacco, and form a fundamental component of healthcare services. ${ }^{[22]}$

The FCTC reinforces the key position of smoking cessation in healthcare services. In article 14, it provides that parties must develop programmes that promote the cessation of tobacco use, including diagnosis and treatment for tobacco dependence, providing counselling services and facilitating the accessibility and affordability of treatment for tobacco dependence. ${ }^{[21]}$

The human right to access healthcare services has the potential to fuel the right to tobacco dependence interventions as a legitimate claim, and gives rise to corresponding obligations on the state. Cabrera and Madrazo $^{[25]}$ assert that to fulfil the obligations of the right to health, states must implement measures and budgetary allocations favourable for tobacco control, including treatment for 'people afflicted by diseases stemming from tobacco use, [and] facilitating smokers' access to cessation programmes.'

The right in section 27 is that of access to healthcare, and accordingly, accessibility is an essential qualifier. ${ }^{[18]}$ To pass the test of accessibility, smoking cessation services must be reasonable, available, comprehensive and affordable. ${ }^{[18]}$ Reasonable smoking cessation programmes and measures must be adopted and implemented. A key element of tobacco control legislation is supposed to direct smoking cessation programmes, and the lack of this provision in legislation should instantly raise a red flag about the reasonability of the policy. The SA Tobacco Products Control Act No. 83 of 1993 recognises that tobacco use has caused widespread addiction in society, ${ }^{[26]}$ but it does not address treatment for tobacco dependence. Even the recent proposed Tobacco Control Bill, which proposes advanced plain packaging measures, does not deal with nicotine addiction and treatment. ${ }^{[27]}$ This instantaneously raises concerns regarding the reasonability of the smoking cessation programme in SA.

To be reasonable, the smoking cessation programme must be comprehensive, and not exclude the people in need of the protection of their right to access healthcare services. ${ }^{[2]]}$ Behavioural counselling must be available at primary healthcare institutions. Pharmacotherapy must be affordable, and must not exclude the economically disadvantaged. ${ }^{[9]}$ This is crucial, considering that pharmacotherapy is more expensive to obtain than tobacco products. ${ }^{[9]}$
The smoking cessation programme must also show progress towards the attainment of its objectives. The right under section 27(1)(a) compels the state to demonstrate the progressive realisation of the goal. ${ }^{[18]}$ In this case, it must show a reduction of tobacco consumption among current smokers, or successful quit attempts, and in turn, contribute to the broader goal of curbing the tobacco epidemic.

Lastly, the right to access smoking cessation services is qualified by the availability of resources, which is line with the CESCR's observations that the context of healthcare services depends on the state's level of development. ${ }^{[18]}$ Although this presents a limitation on the provision of smoking cessation services, the state has the duty to justify its use of public resources. ${ }^{[18]}$ Budgeting and resource allocations can be scrutinised. ${ }^{[18]}$ Of importance within the smoking cessation context is the fact that evidence has shown that treating dependent smokers is one of the most cost-effective interventions that a healthcare system can provide ${ }^{[9]}$ Behavioural support would require resources to train the smoking cessation counsellors, and pharmacotherapy could be costly at the initiation. ${ }^{[9]}$ However, for states still struggling with resource allocation, smoking cessation, 'relative to other public health measures, can offer the greatest returns on a state's investment. ${ }^{[9]}$ Resources currently used for curative care would eventually be freed up for other pressing needs.

Furthermore, for a country struggling with a high disease burden resulting from the HIV/AIDS pandemic, smoking cessation should be a priority. ${ }^{[2,4]}$ Smoking cessation is an important and effective intervention in individuals living with HIV and TB. ${ }^{[2,4]}$ Preventive care could be cheaper in the long run, as the cost of smoking-related diseases that would require curative care would be much greater for SA than preventive smoking cessation programmes. ${ }^{[8]}$ These factors should push the state to improve access to smoking cessation for thousands of smokers in SA. The cost-effective nature of smoking cessation treatment also increases the burden on the state to justify its failure to devote appropriate resources.

In its existing state, the smoking cessation programme is limited, inconsistent and shows signs of neglect. Unless the state can prove that the current smoking cessation programme is accessible to the extent that the resources permit, it is in violation of the right to access healthcare.

\section{Conclusion}

Tobacco consumption creates health-related problems that require urgent attention, and its control is a prerequisite for the realisation of other human rights. Accordingly, smoking cessation services hold a key position in the healthcare system. Section 27 of the Constitution of SA strengthens the position of tobacco dependence interventions: as healthcare services, section 27 compels the state to provide access to smoking cessation programmes that are reasonable, comprehensive, affordable and appropriate. It also imposes positive obligations on the state to ensure that the programmes receive an appropriate budget.

This article concludes that there is a right to access healthcare services in SA, of which tobacco dependence interventions are an important subset. Furthermore, this section 27 right to accessible healthcare can substantiate calls for improved access to smoking cessation services. 
Acknowledgements. None.

Author contributions. Sole author.

Funding. None.

Conflicts of interest. None.

1. Chaloupka FJ, Warner K. The economics of smoking. In: Culyer A, Newhouse J, eds. Handbook of Health Economics. Amsterdam: Elsevier; 2000;1539-1627.

2. Van Zyl-Smit RN, Allwood B, Stickells D, Symons G, Abdool-Gaffar S, Murphy K. South African tobacco smoking cessation clinical practical guideline. S Afr Med J 2013;103(11): 869 -876. https://doi.org/10.7196/samj.7484

3. Business Tech. Here's how many South Africans still smoke every day. Business Tech, 13 March 2018. https://businesstech.co.za/news/lifestyle/231261/hereshow-many-south-africans-still-smoke-every-day/ (accessed 10 November 2018).

4. Schellack N, Bronkhorst E. Smoking cessation. S Afr Fam Pract 2015;57(1):39-42.

5. Cosci F, Pistelli F, Lazzarini N, Carrozzi L. Nicotine dependence and psychological distress: Outcomes and clinical implications in smoking cessation. Psychol Res Behav Manag 2011;4:119-128. https://doi.org/10.2147/PRBM.S14243.

6. World Health Organization. WHO report on the global tobacco epidemic 2017: Country profile South Africa. Geneva:WHO, 2017. https://www.who.int/tobacco/ surveillance/policy/country_profile/zaf.pdf (accessed 20 March 2019).

7. World Health Organization. Fact sheet about health benefits of smoking cessation. Geneva: WHO. http://www.who.int/tobacco/quitting/benefits/en/ (accessed 17 June 2017).

8. Van Zyl-Smith RN. Hopeful evidence: Smoking cessation medication. https:// www.phasa.org.za/hopeful-evidence-smoking-cessation-medication (accessed 10 August 2018).

9. Meir BM. Breathing life into the FCTC: Smoking cessation and the right to health. Yale J Health Pol L Ethics 2013;5(1):137-192.

10. GOV.UK. Health matters: Stopping smoking - what works? London: GOV.UK, 2018. https://www.gov.uk/government/publications/health-matters-stoppingsmoking-what-works/health-matters-stopping-smoking-what-works (accessed 18 April 2019).

11. Evans DB, Hsu J, Boerma T. Universal health coverage and universal access. Bull World Health Org 2013;91:546-546A. http://doi.org/10.2471/BLT.13.125450

12. Raw M, McNeill A. Tobacco dependence treatment in England. Geneva: World Health Organization, 2003. https://www.who.int/tobacco/publications/smoking cessation/en/best_practices_england.pdf?ua=1 (accessed 2 March 2019).

13. Cancer Association of South Africa. https://www.cansa.org.za/how-to-quitsmoking-and-why/ (accessed 20 December 2017).
14. National Council Against Smoking. Why should you stop smoking? http://www. againstsmoking.co.za/tag/why-should-you-stop-smoking-2/ (accessed 25 October 2018).

15. Saloojee Y. Tobacco control in South Africa. In: Steyn K, Fourie J, Temple N (eds). Chronic Diseases of Lifestyle in South Africa since 1995 - 2005. Technical Report. Cape Town: South African Medical Research Council, 2006:48-57. http://www. mrc.ac.za/sites/default/files/files/2016-07-14/cdl1995-2005.pdf (accessed 20 December 2017).

16. Okeke PI, Ross AJ, Esterhuizen T, van Wyk JM. Tobacco and alcohol use among healthcare workers in three public hospitals in KwaZulu-Natal, South Africa. S Afr Fam Pract 2012; 54(1):61-67.

17. Constitution of the Republic of South Africa. 1996.

18. Currie I, de Waal J. Bill of Rights Handbook. 6th edition. Cape Town: Juta \& Co, 2013.

19. Roger P. South Africa's right to healthcare: International and constitutional duties in relation to the HIV/AIDS epidemic. Human Rights Brief 2004;11(2): 9-12.

20. United Nations General Assembly. International Covenant on Economic, Social and Cultural Rights. Resolution 2200 A (XX) of December 16, 1966. https://www. ohchr.org/en/professionalinterest/pages/cescr.aspx (accessed 1 August 2018).

21. Framework Convention on Tobacco Control. WHO [World Health Organization] framework convention on tobacco control Geneva: WHO, 21 May 2003. http:// whqlibdoc.who.int/publications/2003/9241591013.pdf (accessed 1 August 2018).

22. United Nations Committee on Economic and Social and Cultural Rights. General comment 14 on the right to the highest attainable standard of health (twenty-second session, 2000. Geneva: UN, 2000. https://www.refworld.org/ pdfid/4538838d0.pdf (accessed 1 August 2018).

23. Pieterse M. Can rights cure? The impact of human rights litigation on South Africa's health system. Pretoria: University Law Press, 2014;20.

24. Liberman J. The power of the WHO FCTC: Understanding its legal status and weight. In: Mitchell AD, Voon T, eds. The Global Tobacco Epidemic and the Law. Northampton, Mass.: Edward Elgar, 2014:49-63.

25. Cabrera OA, Madrazo A. Human rights as a tool for tobacco control in LatinAmerica. Salud Pública de México 2010;52(Suplemento 2):S291-S292.

26. South Africa. Tobacco Products Control Act No. 83 of 1993.

27. South Africa. The Control of Tobacco Products and Electronic Delivery Systems Draft Bill of 2018. GG 416179 May 2018.

Accepted 18 June 2019. 